NASA Contractor Report 182147

\title{
Hypersonic Turbulent Wall Boundary Layer Computations
}

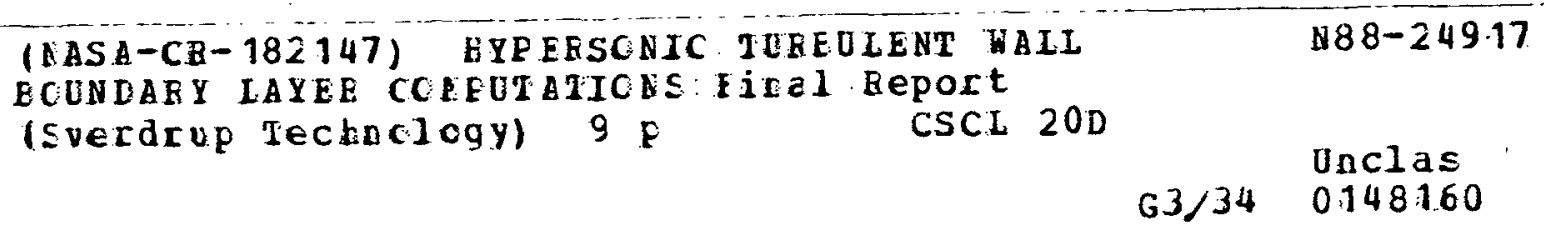

S.C. Kim and G.J. Harloff

Sverdrup Technology, Inc.

(Lewis Research Center Group)

NASA Lewis Research Center

Cleveland, Ohio

May 1988

Prepared for

Lewis Research Center

Under Contract NAS3-25266

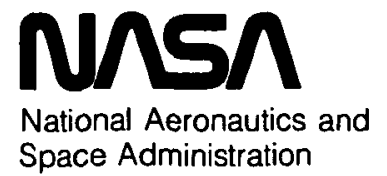




\title{
HYPERSONIC TURBULENT WALL BOUNDARY LAYER COMPUTATIONS
}

\author{
S.C. Kim* and G.J. Harloff**
}

Sverdrup Technology, Inc. (Lewis Research Center Group)

NASA Lewis Research Center

Cleveland, Ohio 44135

\begin{abstract}
The Baldwin-Lomax algebraic turbulence model was modified for hypersonic flow conditions. Two coefficients in the outer-layer eddy-viscosity model were determined as functions of Mach number and temperature ratio. By matching the solutions from the Baldwin-Lomax model to those from the Cebeci-Smith model for a flat plate at hypersonic speed, the new values of the coefficients were obtained. The results show that the values of $C_{c p}$ and $C_{k l e b}$ are functions of both Mach number and wall temperature ratio. The $C_{c p}$ and $C_{k l e b}$ variations with Mach number and wall temperature were used for the calculations of both a $4^{\circ}$ wedge flow at Mach 18 and an axisymmetric Mach 20 nozzle flow. The Navier-Stokes equations with thin-layer approximation were solved for the above hypersonic flow conditions and the results were compared with existing experimental data. The agreement between the numerical solutions and the existing experimental data were good. The modified Baldwin-Lomax model thus is useful in the computations of hypersonic flows.
\end{abstract}

\section{Introduction}

With recent interest in hypersonic light, the flow phenomena at high Mach number are gaining the attentions of both experimental and computational fluid dynamics communities. There has been much progress in turbulence modeling for incompressible flows, but little progress in high speed flow. For hypersonic turbulent boundary layer calculations, most investigators have used algebraic turbulence models for their simplicity, and a popular model is the Baldwin-Lomax model ${ }^{1}$ which was patterned after the Cebeci-Smith model ${ }^{2}$. It uses the same inner-layer eddyviscosity formula as the Cebeci-Smith model, but it does not require the finding of the edge of the boundary layer for the outer-layer eddy-viscosity calculation.

There are two coefficients in the outer-layer eddyviscosity formula of the Baldwin-Lomax turbulence model for attached wall boundary layer. Their values were obtained by matching the outer-layer eddy-viscosity with that from the Cebeci-Smith model at transonic

\footnotetext{
*Hypersonics Research Engineer, Member AIAA.

* Supervisor, Hypersonic Analysis, Senior Member AIAA.
}

flow conditions ${ }^{1}$. Their suggested values at these conditions are 1.6 for $C_{c p}$ and 0.3 for $C_{k l e b}$. Several authors have suggested different values for the coefficients, depending on Mach number and pressure gradient $(3,4,5,6)$. As free-stream Mach number increases, the sublayer thickness increases and this growth of sublayer becomes significant at hypersonic. Mach numbers. To obtain the same performance of the Baldwin-Lomax model as that of the CebeciSmith model, the two coefficients should be adjusted with Mach number and wall temperature ratio.

Previous investigators have examined the variation of $C_{c p}$ and $C_{k l e b}$ with pressure gradient, Mach number, and surface blowing. Table 1 lists variations of $C_{c p}$ from 0.85 to 1.82 and variations of $C_{k l e b}$ from .3 to .65 . Granville determined the pressure gradient effects on both of the coefficients for incompressible flow. York and Knight found that both the coefficients depend on local Mach number, local skin-friction, and the pressure parameter. York and Knight's investigation included the flows up to Mach 5. The present authors did not find in the literature any evaluations of the coefficients in the Baldwin-Lomax model at hypersonic speeds. The above studies suggest that $C_{c p}$ and $C_{k i e b}$ should be adjusted with the local flowfield. However, at the present time it is typical to use fixed coefficients in the Baldwin-Lomax turbulence model. It is an objective of this study to determine the variation of these coefficients with Mach number and wall temperature ratio.

To study the variation of the coefficients in the Baldwin- Lomax model, the boundary layer over a flat plate was solved with the Baldwin-Lomax model and the results were compared with those from the CebeciSmith model. By matching the skin friction coefficients and boundary layer thicknesses from the Baldwin- Lomax model to those from the Cebeci-Smith model, new coefficients were obtained at different Mach numbers. These new coefficients were used for the calculations of the flows over a wedge and in a nozzle at hypersonic Mach numbers, and the results were compared with experimental data.

\section{Turbulence models}

Cebeci-Smith model

The Cebeci-Smith model can be written as follows:

$$
\mu_{t}=\min \left(\mu_{t i}, \mu_{t 0}\right)
$$




$$
\begin{gathered}
\mu_{t i}=\rho l^{2}\left|\frac{\partial u}{\partial y}\right| \\
l=0.4 y\left(1-\exp \left(\frac{-y^{+}}{A^{+}}\right)\right) \\
y^{+}=\frac{u_{r} y}{\nu_{w}}, u_{r}=\sqrt{\frac{\left|r_{w}\right|}{\rho_{w}}} \\
\mu_{t 0}=\frac{\rho k_{1} u_{e} \delta_{i n e}^{*}}{1+\delta .5(\xi)^{6}}
\end{gathered}
$$

where $\delta_{\text {inc }}^{*}$ is the incompressible form of boundary layer displacement thickness, $A^{+}$is the van Driest's damping factor $(=26)$ and $k_{1}$ is constant(=.0168).

\section{Baldwin-Lomax model}

The Baldwin-Lomax model can be written as follows:

$$
\begin{gathered}
\mu_{t}=\min \left(\mu_{t i}, \mu_{t 0}\right) \\
\mu_{t i}=\rho l^{2}|\omega| \\
\mu_{t 0}=k_{1} C_{c p} \rho F_{w a k e} F_{k l a b} \\
F_{\text {wake }}=\min \left(y_{\max } F_{\text {max }}, C_{w k} y_{\text {max }} \frac{U_{d i f}^{2}}{F_{\text {max }}}\right) \\
F_{k l e b}=\frac{1}{1+5.5\left(\frac{\left.C_{\text {klabs }}\right)^{6}}{y_{\text {mas }}}\right.}
\end{gathered}
$$

where $C_{c p}$ is 1.6, $C_{k l e b}$ is $.3, C_{w k}$ is 0.25 , and $\omega$ is the vorticity. The values of $y_{\max }$ and $F_{\max }$ are obtained from the following function:

$$
F=y|\omega|\left(1-\exp \left(\frac{-y^{+}}{A^{+}}\right)\right)
$$

and the value of $U_{d i}$ is the difference between the maximum and minimum total velocities in the profile.

As seen from the above formulas, the Baldwin-Lomax model is nearly same os the Cebeci-Smith model for the inner-layer. For outer-layer formulas, the following relations can be obtained by matching the above two models:

$$
\begin{gathered}
C_{c p}=\frac{u_{e} \delta_{\text {ine }}^{*}}{\left(y_{\max } F_{\max }\right)} \\
C_{k l e b}=\frac{y_{\max }}{\delta}
\end{gathered}
$$

As seen from Eq. 12, $C_{c p}$ is a function of the incompressible form of the displacement thickness. As Mach number increases, the contribution to $\delta_{\text {ine }}^{*}$ from the viscous sublayer becomes significant. Unless $y_{\max }$ and $F_{\max }$ contain the effect of the growth of the viscous sublayer, $C_{c p}$ is functions of both Mach number and wall temperature ratio.

\section{$\underline{C_{c p} \text { and } C_{k l e b} \text { variations }}$}

To study the variations of $C_{c p}$ and $C_{k l e b}$ with Mach number and wall temperature ratio, a turbulent boundary layer over a flat plate was solved by the STAN5 program ${ }^{7}$. By matching boundary thickness and skin friction coefficient from the Baldwin-Lomax model to those from the Cebeci-Smith model, $C_{c p}$ and $C_{k l e b}$ variations with Mach number and wall temperature ratio were obtained. For simplicity, the Klebanoff intermittency factor was assumed to be unity because main interest is in hypersonic flow $^{8}$.

Figure 1 shows the variation of $C_{c p}$ with Mach number for the following conditions.

$$
\begin{aligned}
& \text { Flat plate } \\
& \text { Adiabatic wall, helium } \\
& T_{e}=7^{\circ} \mathrm{K} \\
& R_{e x}=9.4 \times 10^{7}
\end{aligned}
$$

For the calculation of laminar viscosity of helium, the following viscosity laws were used:

$$
\begin{gathered}
\mu=5.023\left(\frac{T^{1.647}}{T+0.83}\right) \times 10^{-7} \quad\left(\frac{N s}{m^{2}}\right)\left(T<8^{\circ} K\right) \\
\mu=5.0277 \times 10^{-7} T^{0.647}\left(\frac{N s}{m^{2}}\right)
\end{gathered}
$$

and the turbulent Prandtl number was assumed to be constant, 0.9 .

As seen from Figure 1, $C_{\mathfrak{c p}}$ increases from 1.5 to 3.0 as Mach number increases from 0 to 13. This increase in $C_{c p}$ with free-stream Mach number is mainly due to the growth of sublayer. Figure 2 shows the variation of $C_{k l e b}$ with Mach number at the above condition. As seen from this Figure, $C_{k l e b}$ decreases with Mach number up to $M=5$ and stays nearly constant. This variation shows that $\frac{1 \max ^{\prime}}{\delta}$ is nearly constant at hypersonic Mach number range.

Figure. 3 and 4 show the variations of $C_{c p}$ and $C_{k l e b}$ with Mach number for fully developed turbulent boundary layer over a flat plate for the following conditions:

$$
\begin{aligned}
& \text { Flat plate } \\
& \text { Helium. } \\
& \text { Adiabatic wall and } \frac{T_{u}}{T_{00}}=.6 \\
& T_{o s}=500^{\circ} \mathrm{K}, P_{o e}=270 \text { atm. }
\end{aligned}
$$

In this case, the free-stream conditions were obtained from isentropic relations and the Reynolds number range is from $1.4 \times 10^{8}$ to $17 \times 10^{8}$.

Figure 3 shows the variations of $C_{c p}$ with Mach number. As seen from this Figure, $C_{c p}$ increases from about 1.5 at Mach 1 to about 3.0 at Mach 20. The $C_{a p}$ values for the adiabatic conditions are greater than those for the cold wall conditions at Mach numbers higher than 10 . This difference is due to the fact that the viscous sublayer at the adiabatic wall conditions is thicker than that at the cold wall conditions.

Figure 4 shows the variations of $C_{k l e b}$ with Mach number. As seen from this Figure, $C_{k l e b}$ decreases from about 0.6 at Mach 1 to about 0.37 for the adiabatic wall and 0.3 for the cold wall at Mach 20. The $C_{k l e b}$ values for the adiabatic wall conditions were nearly same as those for the 
cold wall conditions up to Mach 8 and the $C_{k i n b}$ values for adiabatic wall conditions are greater than those for cold wall conditions at very high Mach number.

The above study indicates that $C_{o p}$ and $C_{k l e b}$ depend on Mach number and wall temperature ratio and vary from 1.5 to 3.1 and 0.56 to 0.3 , respectively. These variations of $C_{e p}$ and $C_{k l e b}$ were used for the calculation of the hypersonic flows over a wedge and in a nozzle.

\section{Numerical Method and Grid}

An existing computer code, PARC2D, is used for the calculations for hypersonic tows over a wedge and in a nozzle. The code solves the two-dimensional Reynolds averaged Navier-Stokes equations with the Beam and Warming algorithm. The code was originally developed as AIR2D by Pulliam and Steger ${ }^{\circ}$, and it was called ARC2D after the Jameson type artificial dissipation ${ }^{10}$ was added by Pulliam ${ }^{11}$. Later, Cooper adapted the ARC2D code for propulsion applications and named the code PARC2D ${ }^{12}$.

Algebraically generated grids are used for the calculations. The meshes are clustered near the wall with 100 points vertically. The computational domain consists of uniform grid spacing up to $x=1 m$ and stretched grid spacing when $x>1 \mathrm{~m}$ in the streamwise direction, and the grid contains $150 \times 100$ points for the wedge flow calculations. For the nozzle flow calculations, clustered grids in the streamwise direction are used near the throat. The grid size is $100 \times 100$ for the nozzle flow.

\section{Experimental Data}

To compare the numerical solutions with the experimental data, the following two cases were selected.

\section{1) Hypersonic flow over $4^{\circ}$ wedge $e^{18}$}

This experiment was conducted in the Mach $20 \mathrm{leg}$ of the Langley high Reynolds number hellum tunnel by Watson and the test conditions are as follows:

$$
\begin{aligned}
& \text { Helium. } \\
& P_{t}=136 \mathrm{~atm} \\
& T_{t}=311^{\circ} \mathrm{K} \\
& M_{1}=18.05 \\
& \frac{T_{v}}{T_{1}}=.95 \\
& \frac{R_{t}}{m}=4.36 \times 10^{7} / \mathrm{m}
\end{aligned}
$$

Transition starts at $x=.36 \mathrm{~m}$ and ends at $x=.89 \mathrm{~m}$. For this wedge flow case, the shear atress at the wall, velocity and temperature profiles are known. The numerical solutions were compared with wall shear stress distribution and with velocity and temperature profiles at $x=2.159$ m.

2) Axisymmetric contoured hypersonic nozzle flow ${ }^{14}$.

For this case, the experimental data were obtained by Kemp and Owen in the Ames M-50 helium tunnel. The test condition is as follows:

$$
\begin{aligned}
& \text { Helium. } \\
& P_{t}=270 \text { atm. }
\end{aligned}
$$

$$
\begin{aligned}
& T_{t}=500^{\circ} \mathrm{K} \\
& T_{w}=300^{\circ} \mathrm{K} \\
& M_{\text {exit }}=20
\end{aligned}
$$

For this case, the velocity and temperature profiles at $x=0.508$ were compared with the numerical solutions.

\section{Modifications to Baldwin-Lomax Model}

As previously mentioned, the values of $C_{c p}$ and $C_{k l e b}$ obtained for a flat plate were used for the calculations. Additionally, the following modifications were added to the Baldwin-Lomax model.

\section{1) Intermittency factor}

Experimental data show that the intermittency factor for hypersonic turbulent boundary layer is quite different from the incompressible one $e^{(8,13)}$. Instead of showing the variation of Eq. 5, the intermittency factor stays nearly unity within the boundary layer and drops very sharply to zero at the edge of the boundary layer. To include the above intermittency variation within the boundary layer, the intermittency factor is assumed to be unity up to $\delta=\frac{y_{m a s}}{C_{k 1}}$ and drop to zero at the edge of the boundary layer.

2) Low Reynolds number effect

To include the low Reynolds number effect on $k_{1}$ in the outer layer formula, Eq. 8, the following modification was used $^{15}$;

$$
\begin{gathered}
k_{1}=\frac{.0168(1+0.55)}{(1+\Pi)} \\
\Pi=.55\left(1-\exp \left(-0.243 Z^{\frac{1}{2}}-0.298 Z\right)\right) \\
Z=\frac{R_{\mathrm{e} \theta}}{425}-1.0
\end{gathered}
$$

where $I I$ is the strength of the wake and $R_{e \theta}$ is the momentum thickness Reynolds number of the boundary layer. To calculate the momentum thickness of boundary layer, it was assumed that the point where $y$ is $\frac{y_{\text {max }}}{C_{k l o b}}$ is the edge of the boundary layer.

3) Pressure gradient effect on $\mathrm{A}^{+}$

To include the pressure gradient effect, the following modified van Driest's damping constant by Launder ${ }^{1 \theta}$ was used:

$$
A^{+}=\frac{26}{\left(\frac{r}{r_{u}}\right)^{1.7}}
$$

where $\tau$ is the local shear stress.

\section{Comparison with Experimental Data}

Calculations were carried out for the above hypersonic flow conditions with PARC2D code with thin-layer approximation using the Baldwin-Lomax turbulence model with the above modifications.

1) Hypersonic wedge flow

To calculate both laminar and turbulent boundary layers, the turbulent viscosity was turned on at the mid- 
point between the beginning point and the end point of the experimentally determined transition $(x=.61 \mathrm{~m})$,e.g. instantaneous transition was assumed.

Figure 5 shows the Mach number contour for the $4^{\circ}$ wedge flow at free-stream Mach number of 18.05. The shock wave and boundary layer can be observed from this figure. The shear stress at the wall is shown in figure 6. As seen from this figure, the flow starts from laminar and becomes turbulent at far downstream. The agreement between calculations and experimental data is reasonably good and the difference is less than $20 \%$ at $x=2.159 \mathrm{~m}$. This difference seems to be due to the transition model and transition point. A better transition model, such as a precursor transition model, might improve the numerical solutions.

The velocity and temperature profiles at $x=2.159 \mathrm{~m}$ are given in Figures 7 and 8. At this station, the flow is fully turbulent and the leading edge shock wave is located at $y=0.15 \mathrm{~m}$. As seen from these figures, the calculated profiles agree relatively well with the test data.

\section{2) Hypersonic nozzle flow}

The Mach number contour for the hypersonic nozzle is given in Figure 9. The flow expands from sonic at the throat to about Mach 20 at $x=.508 \mathrm{~m}$ as seen from this figure. The velocity and temperature profiles at $x=.508$ $m$ are shown in Figures 10 and 11 . As seen from these figures, the profiles from present numerical solutions agree well with the data. The computed shear stress at the wall at $\mathrm{x}=0.508 \mathrm{~m}$ was $10.21 \mathrm{~N} / \mathrm{m}^{2}$, and the experimental data give the value of $10.60 \mathrm{~N} / \mathrm{m}^{2}$

\section{Summary and Conclusions}

By solving the boundary layer equations for a flat plate at hypersonic speed, the variations of $C_{\mathrm{cp}}$ and $C_{k l e b}$ in the Baldwin-Lomax model with Mach number and wall temperature ratio were determined. By matching the solutions from Baldwin-Lomax model with those from CebeciSmith model, the new variations of the coefficients were obtained. The results show that the values of $C_{c p}$ and $C_{k l e b}$ are functions of both Mach number and wall temperature ratio. $C_{c p}$ increases with Mach number and $C_{c p}$ for the adiabatic wall case is higher than that for the cold wall case. The variation of $C_{k l e b}$ shows that $C_{k l e b}$ decreases with Mach number up to 5 and stays nearly constant when Mach number is greater than 5. The variations of $C_{c p}$ and $C_{k l e b}$ were used for the calculations of hypersonic llows for both $a 4^{\circ}$ wedge and a nozzle. The solutions obtained by solving Navier-Stokes equations compared well with experimental data.

\section{References}

[1.] Baldwin, B.S. and Lomax; H., "Thin Layer Approximation and Algebraic Model for Separated Turbulent Flows," AIAA Paper 78-257, 1978.

[2.] Cebeci, T. and Smith, A. M. O., Analysis of Turbulent Boundary Layers, Academic Press, 1974.

[3.] Visbal, M. and Knight, D., "The Baldwin-Lomax Turbulence Model for Two-Dimensional ShockWave/Boundary-Layer Interactions, " AIAA Journal, Vol. 22, No.3, pp. 921-928, 1984.

[4.] Stock, H.W. and Haase, W., "The Determination of Turbulent Length Scales in Algebraic Turbulence Models for Attached and Slightly Separated Flows Using Navier-Stokes Methods, " AIAA Paper 87-1302, 1987.

[5.] York, B. and Knight, D., "Two-Dimensional Turbulent Boundary Layers Using the Baldwin-Lomax Model," AIAA Journal, Vol. 23, pp. 1849-1850, 1985.

[6:] Granville, P.S., "Baldwin-Lomax Factors for Turbulent Boundary Layers in Pressure Gradients, " AIAA Journal, Vol.25, No.12, pp. 1024-1627, 1987.

[7.] Crawford, M.E. and Kays, W.M., "STAN5 - A Program for Numerical Computation of Two-Dimensional Internal and External Boundary Layer Flows," NASA CR-2742, 1976.

[8.] Bushnell, D.M. and Cary, A.M.Jr., "Calculation Methods for Compressible Turbulent Boundary Layers - 1976," NASA SP-422, 1977.

[9.] Pulliam, T.H. and Steger, J.L., "Implicit Finite Difference Simulations of Three Dimensional Compressible Flow, ${ }^{n}$ AIAA Journal, Vol. 18, No. 1, pp. 159-167, 1980.

[10.] Jameson, A., Schmidt, W., and Turkel, E., "Numerical Solutions of the Euler Equations by Finite Volume Methods Using Runge-Kutta Time-Stepping Schemes," AIAA Paper 81-1259, 1981.

[11.] Pulliam, T.H., "Euler and Thin Layer Navier-Stokes Codes: ARC2D, ARC3D," Notes for Computational Fluid Dynamics User's Workshop, The University of Tennessee Space Institute, Tullahoma, TN., UTSI Pub. E02-4005-023-84, 1984.

[12.] Cooper, G.K., "The PARC Code: Theory and Usage," AEDC-TR-87-24, 1987.

(13.) Watson, R.D., "Characteristics of Mach 10 Transitional and Turbulent Boundary Layers, "NASA TP$1243,1978$.

[14.] Kemp, J.H. Jr. and Owen, F.K., "Experimental Study of Nozzle Wall Boundary Layers at Mach Numbers 20 to 47 ," NASA TN D-6965, 1972.

[15.] Bradshaw, P., "Topics in Applied Physics, Volume 12. Turbulence," Springer-Verlag, New York, 1978.

[16.] Launder, B.E. and Priddin, C.H., "A Comparison of Some Proposals for the Mixing Length near a Wall, " Int. J. Heat Mass Transfer, Vol. 16, 1973, pp. 700702. 


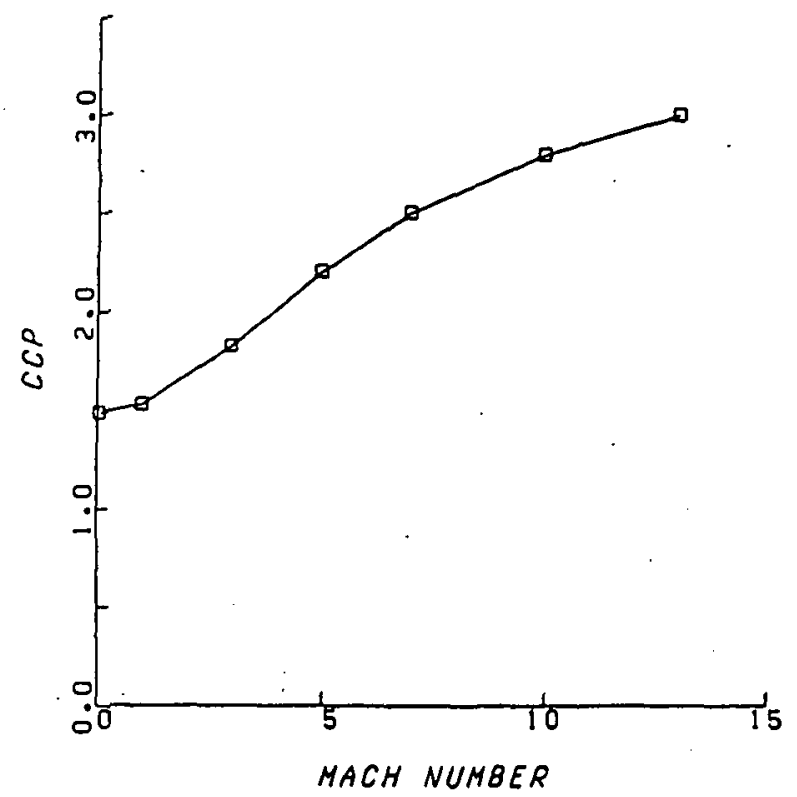

Figure 1. $C_{c p}$ variation with Mach number for a flat plate (adiabatic wall and $R_{e z}=8.4 \times 10^{7}$ ).

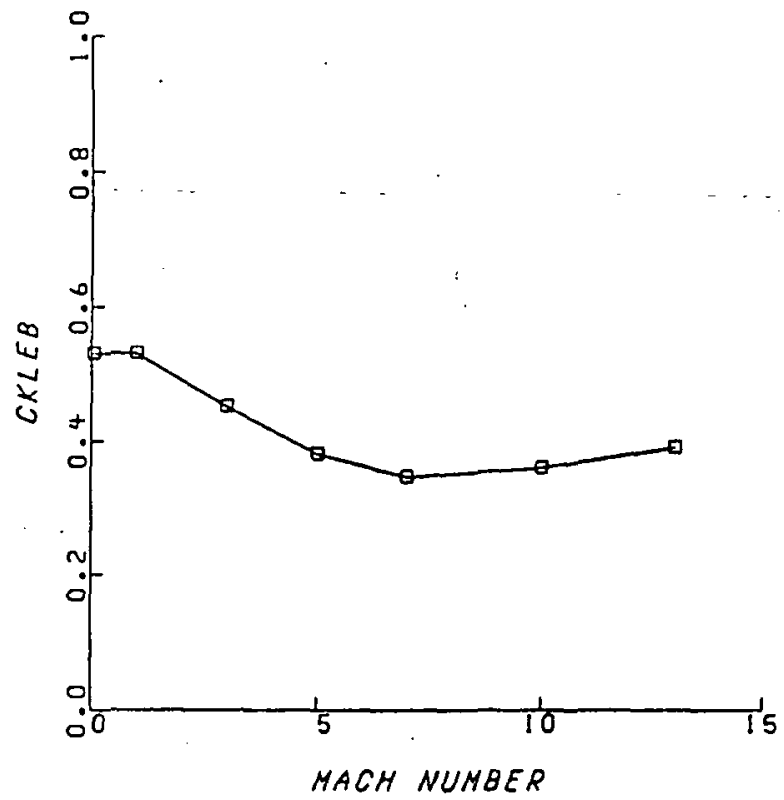

Figure 2. - $C_{k l s b}$ variation with Mach number for a flat plate (adiabatic wall and $R_{a x}=9.4 \times 10^{7}$ ).

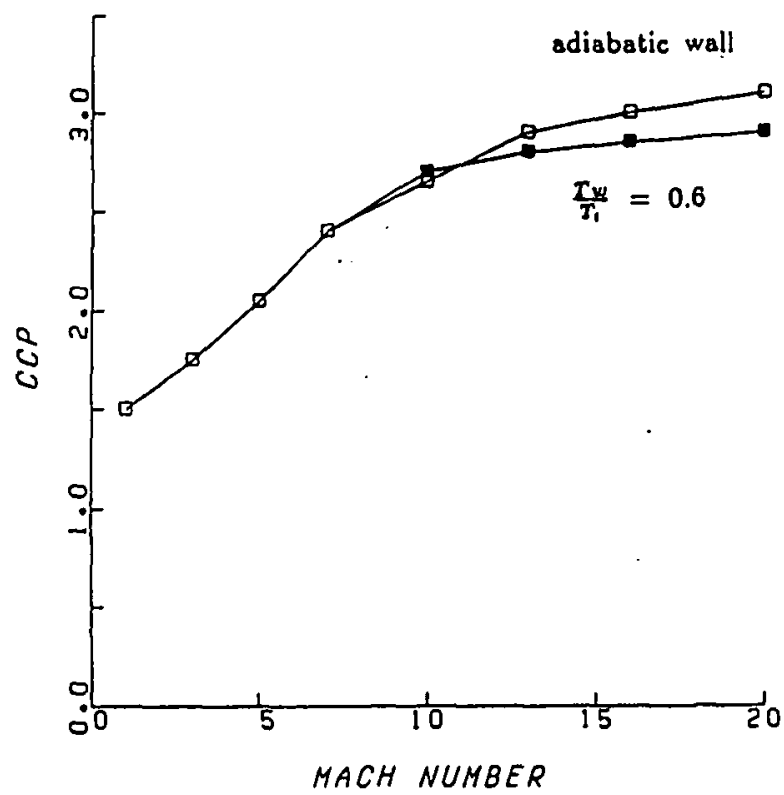

Figure 3. $-C_{c p}$ variations with Mach number and wall temperature ratio (adiabatic wall and $\frac{T w}{T_{t}}=0.6, T_{t}=$ $\left.500^{\circ} \mathrm{K}, P_{t}=270 . a t m\right)$.

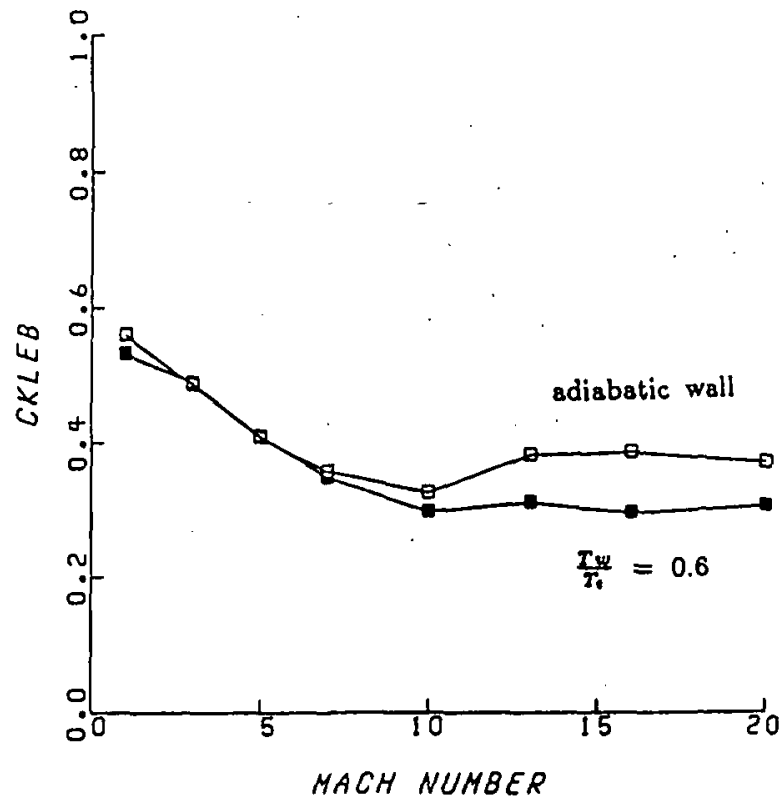

Figure 4. - $C_{k l e b}$ variations with Mach number and wall temperature ratio (adiabatic wall and $\frac{T w}{T_{t}}=0.6, T_{t}=$ $\left.500^{\circ} \mathrm{K}, P_{t}=270 . \mathrm{atm}\right)$. 


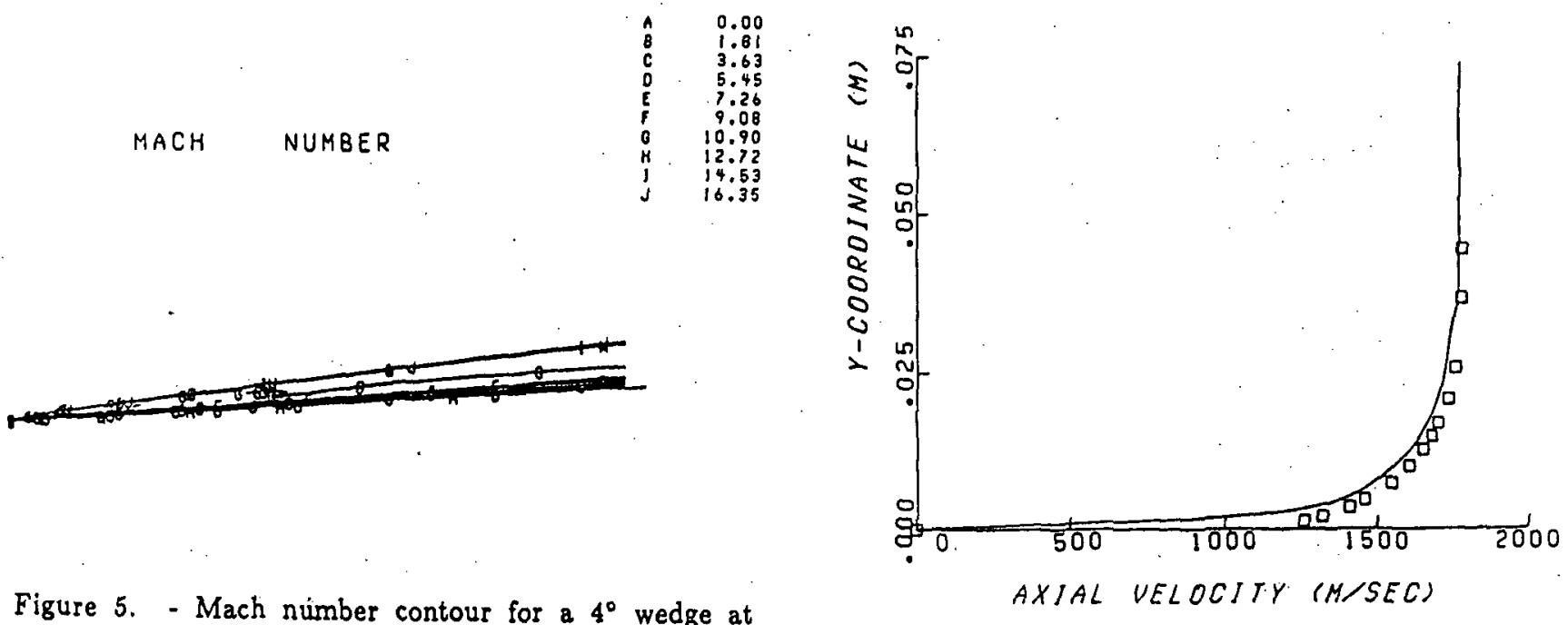
Mach 18.

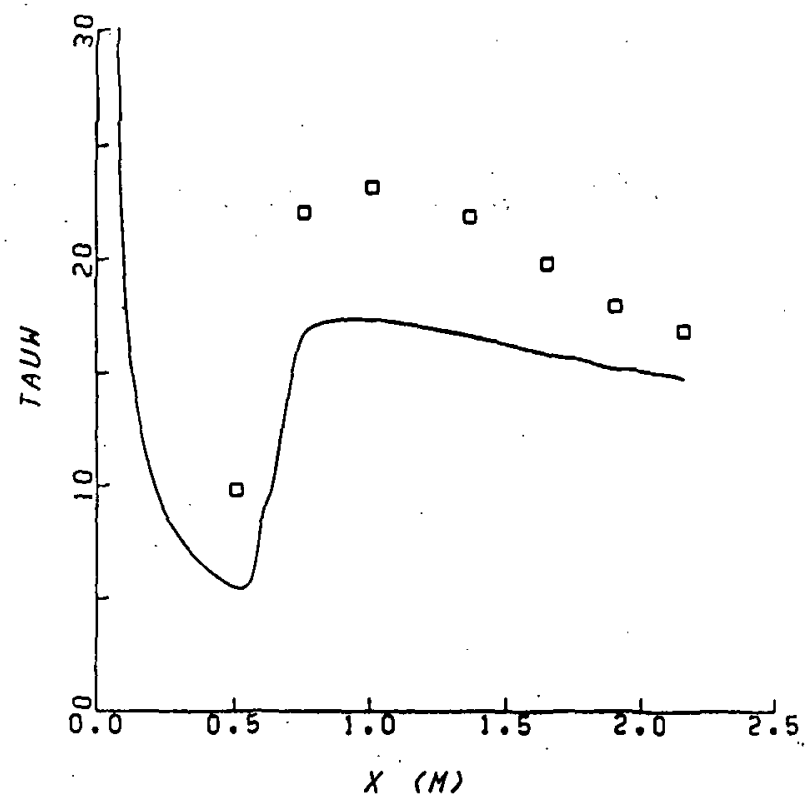

Figure 7. - Velocity profile on a $4^{\circ}$ wedge at $\mathrm{x}=2.16 \mathrm{~m}$.

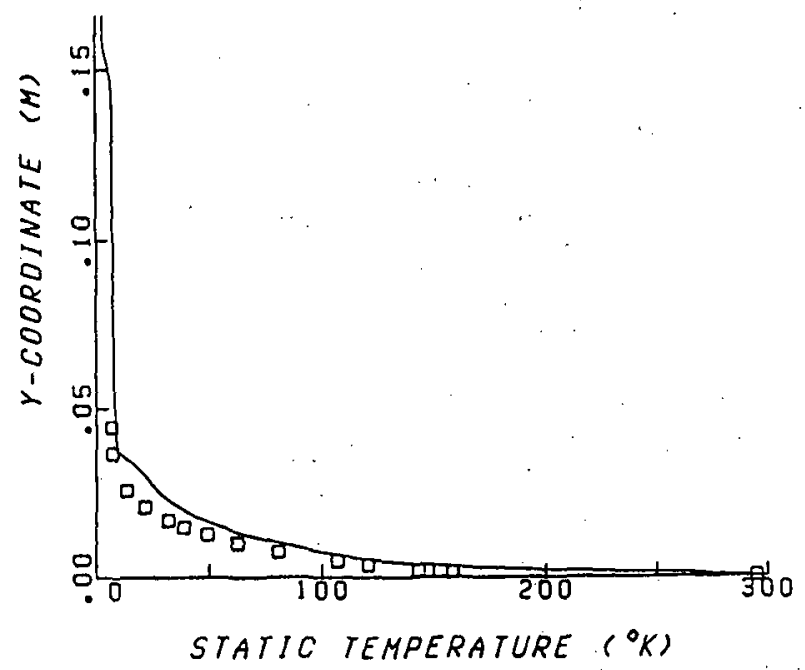

Figure 6. - Shear stress at the wall on a $4^{\circ}$ wedge.

Figure 8, - Temperature profile on a $4^{\circ}$ wedge at $x=$ $2.16 \mathrm{~m}$. 


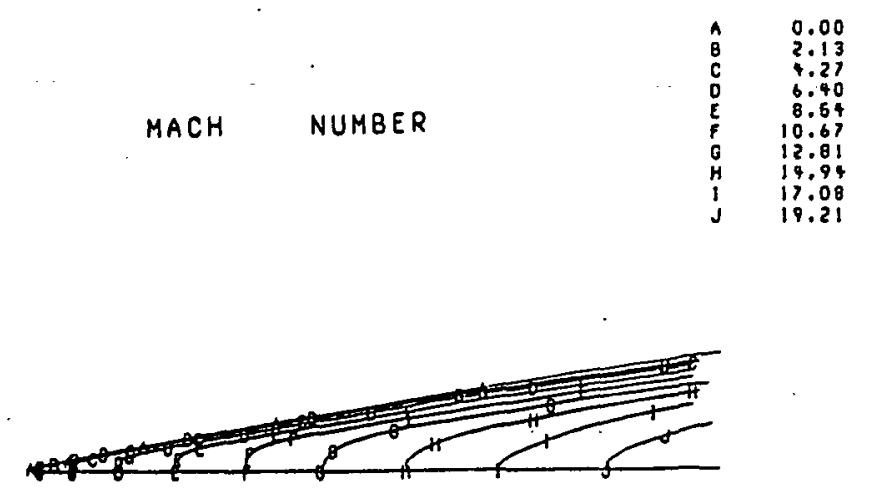

Figure 9. - Mach number contour for a Mach 20 nozzle.

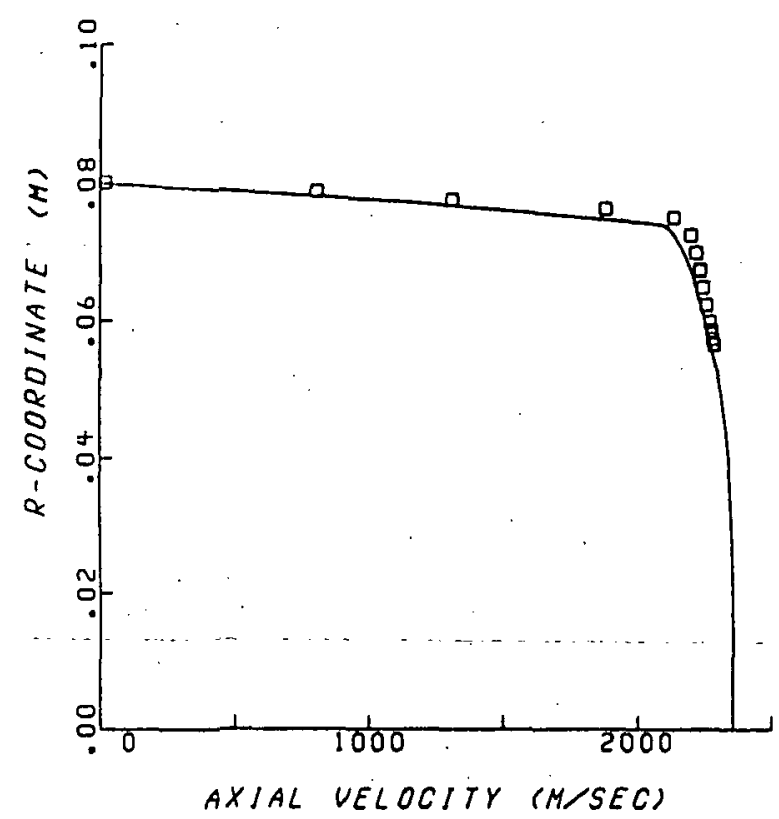

Figure 10. - Velocity profile for a Mach 20 nozzle at $x=$ $0.508 \mathrm{~m}$.

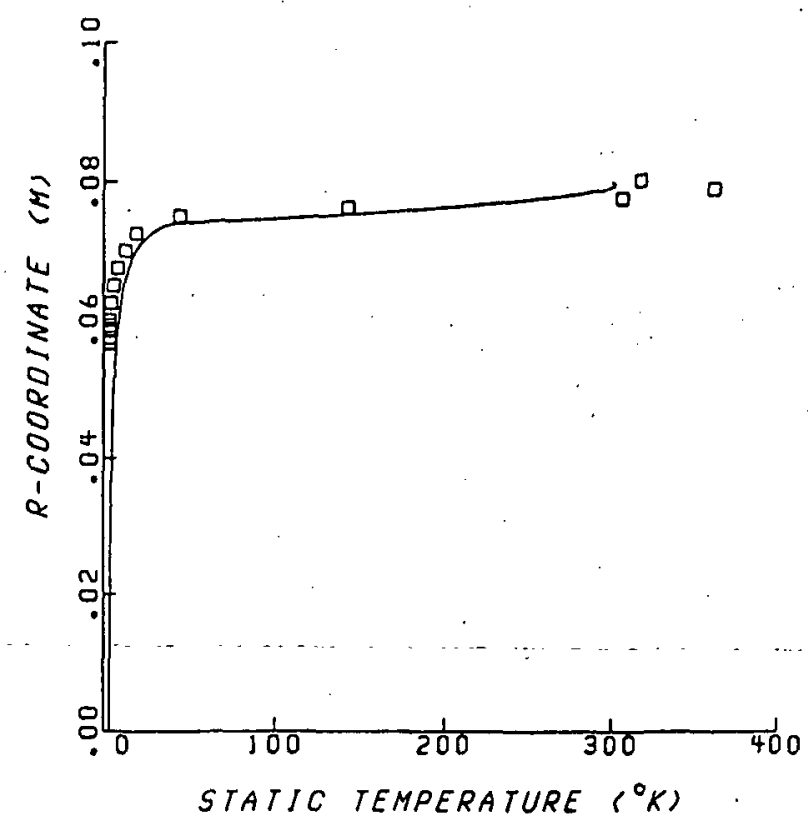

Figure 11. - Temperature profile for a Mach 20 nozzle at $x=0.508 \mathrm{~m}$.

Table 1. Coefficients in Baldwin-Lomax Model

\begin{tabular}{|l|l|l|l|}
\hline Investigators & $C_{\text {ep }}$ & $C_{\text {kleb }}$ & lowfield \\
\hline Baldwin and Lomax & 1.6 & 0.3 & $\mathrm{M}=1$, constant pressure \\
York and Knight $^{\mathrm{b}}$ & $1.15-1.45$ & $.53-.65$ & $0<M<5$, mass addition \\
Granville $^{\mathrm{b}}$ & 1.25 & .59 & $M<<1$, constant pressure \\
Granville $^{\mathrm{b}}$ & $.85-1.82$ & $.44-.64$ & $M<<1$, pressure gradient \\
\hline
\end{tabular}




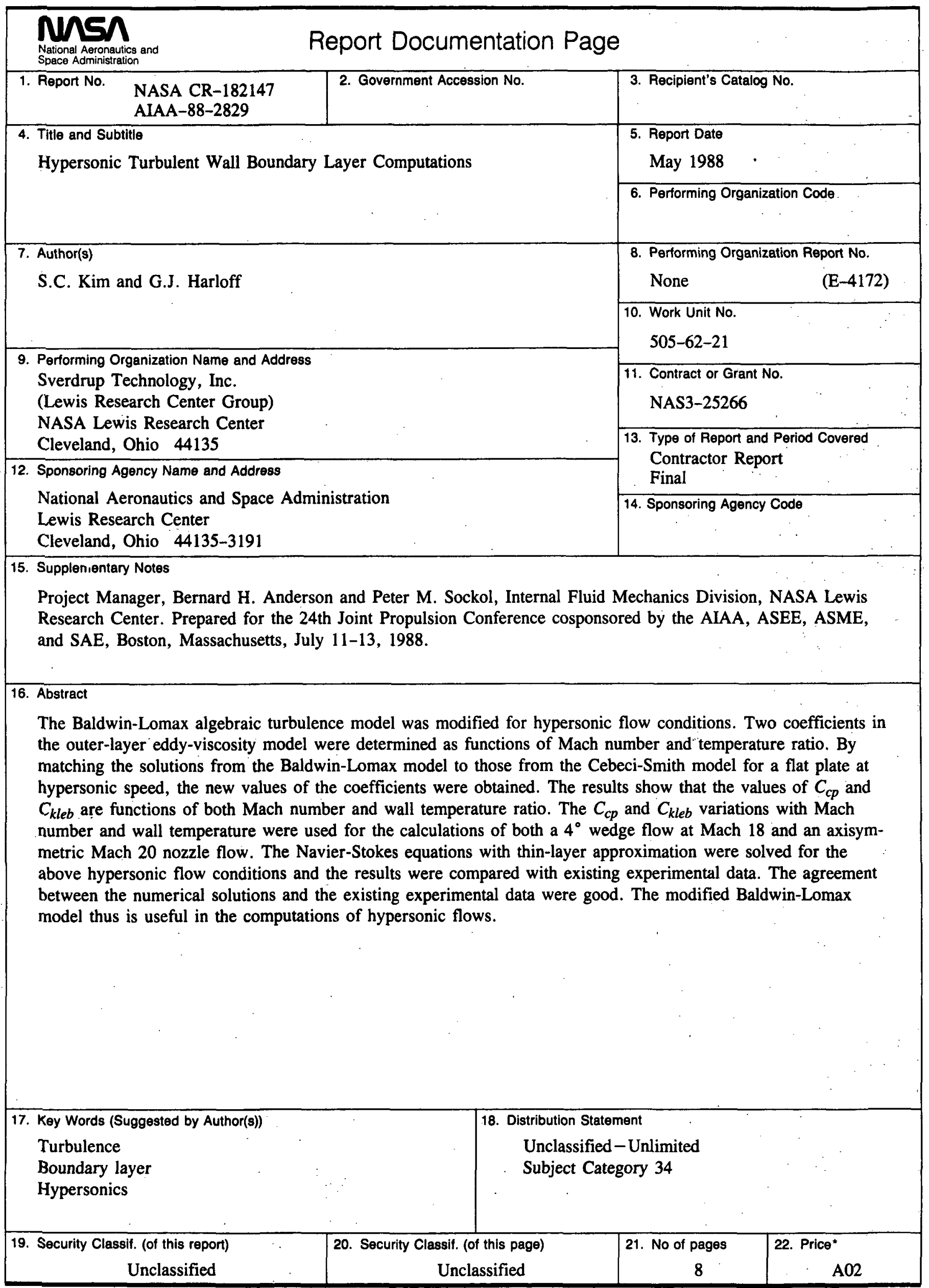

